\title{
Effect of Copper Doping on Structural, Dielectric and DC Electrical Resistivity Properties of $\mathrm{BaTiO}_{3}$
}

\author{
Moganti Venkata Someswara Rao ${ }^{1}$, Kocharlakota Venkata Ramesh ${ }^{2 *}$, \\ Majeti Naga Venkata Ramesh ${ }^{2}$, Bonthula Srinivasa Rao ${ }^{2}$ \\ ${ }^{1}$ Department of Physics, S.R.K.R. Engineering College, Bhimavaram, India \\ ${ }^{2}$ Department of Physics, GIT, GITAM University, Visakhapatnam, India \\ Email: *kv_ramesh5@yahoo.co.in
}

Received January 4, 2013; revised February 12, 2013; accepted February 23, 2013

\begin{abstract}
The modified $\mathrm{BaTiO}_{3}$ ferroelectric materials are suitable for pyroelectric applications. This paper reports the structural, dielectric and electrical properties on copper influence in $\mathrm{BaTiO}_{3}$ when it was substituted site "A" of perovskite structure of $\mathrm{BaTiO}_{3}$. Copper has been chosen for modified $\mathrm{BaTiO}_{3}$ with different concentrations with stoichiometry $\mathrm{Ba}_{1-\mathrm{x}} \mathrm{Cu}_{\mathrm{x}} \mathrm{TiO}_{3}$, where $\mathrm{x}=0.01 \%, 0.02 \%, 0.03 \%$ and $0.04 \%$. The X-ray diffraction patterns of the samples doped with different composition of $\mathrm{CuO}$ are found to be that the positions and intensities of the diffraction peaks are similar and no secondary phases were observed. The Curie's temperature $\left(\mathrm{T}_{\mathrm{c}}\right)$ for all $\mathrm{CuO}$ doped $\mathrm{BaTiO}_{3}$ with were found to be in the range of $120^{\circ} \mathrm{C}$ to $125^{\circ} \mathrm{C}$. The frequency dependence of relative permittivity $\left(\varepsilon_{\mathrm{r}}\right)$ and dielectric loss $(\operatorname{Tan} \delta)$ of $\mathrm{Ba}_{1-\mathrm{x}} \mathrm{Cu}_{\mathrm{x}} \mathrm{TiO}_{3}$ samples at room temperature were reported in the range $100 \mathrm{KHz}-1 \mathrm{MHz}$. The temperature dependence of D.C electrical resistivity studies were reported for all samples indicating that the participation of $\mathrm{Cu}^{2+}-\mathrm{Cu}^{+}$ions in the conduction process around their Curie's temperature.
\end{abstract}

Keywords: Barium Titanate; Copper Doping; Dielectric Properties; DC Electrical Resistivity; Frequency Dependence

\section{Introduction}

Few of crystalline materials which show electrical behavior analogous to the magnetic behavior of ferromagnets are called ferroelectrics. These materials exhibit spontaneous polarization even in the absence of external field because of their spontaneous polarization and hence hysteresis phenomenon. In ferroelectric materials this kind of behavior is observed up to a certain temperature known as Curie's temperature $\left(T_{c}\right)$. This behavior is no more above this $T_{c}$. The dielectric non linearity is one of the significant characteristic of these ferroelectric materials. The structure consisting of the corner linked oxygen octahedral with a small cation filling the octahedral hole and a large cation filling the dodecahedral hole is usually regarded as a perovskite. As a result we can say that perovskite structure has a wide range of substitution of cations A and B, as well as the anions, but remember that the principles of substitution must maintain charge balance and keep sizes within the range for particular co-ordination number. Because the variation of ionic size and small displacement of atoms that lead to the distortion of the structure and the reduction of symmetry have profound effects on physical properties, perovskite struc-

${ }^{*}$ Corresponding author. ture materials play such an important role in dielectric ceramics.

Barium titanate $\left(\mathrm{BaTiO}_{3}\right)$ is one of the best known perovskite ferroelectric compounds $\left(\mathrm{A}^{2+} \mathrm{B}^{4+} \mathrm{O}^{-3}\right)$ that has been extensively studied due to the simplicity of its crystal structure, which can accommodate different types of dopents $[1,2]$. Because of the intrinsic capability of the perovskite structure to host ions of different size, large number different dopents can be accommodated in the lattice [3]. The dopent incorporation mechanism to Ba$\mathrm{TiO}_{3}$ has been extensively studied. The ionic radius is the main parameter that determines the substitution site [4]. Due to their large piezoelectric values, in addition to spontaneous polarization, reversibility of the permanent polarization by an electric field makes them more attractive for different applications. This has led to the possibility of consisting the properties [5] of doped $\mathrm{BaTiO}_{3}$ for specific technological applications, such as capacitors, sensors with positive temperature coefficients of resistivity, transducers and memories [6-9].

This phenomenon is observed in polycrystalline Ba$\mathrm{TiO}_{3}$, with spontaneous polarization of the ferroelectric domains modifying the band-bending and hence the electronic transport across the grain boundary [10]. Doped semi conducting Barium Titanate Ceramics can be as 
positive temperature coefficient (PTC) materials. These act like a switching device [11]. These PTC materials are known to have a high temperature coefficient of resistance around and nearer to Curie temperature and having ability of self-limiting leading to useful for sensor applications.

The present study reports the physical properties with $\mathrm{Cu}$ doped $\mathrm{BaTiO}_{3}$, with different compositions. From the known literature that the $\mathrm{T}_{\mathrm{c}}$ of $\mathrm{BaTiO}_{3}$ is about $120^{\circ} \mathrm{C}$, but it can be modified to correspond with a given application by adjusting the composition and the ceramic microstructure or doping which substitutes in to either $\mathrm{Ba}$ or Ti sites or both. Two types of dopents, one is donor ions which have a higher valance than the ions they replace and the other is acceptor ions which have a lower valance than the ions they replace [12-14]. In the present study the divalent of copper ion is systematically replaced in the place of Barium ion of A site, which is a divalent.

The present paper reports the study of influence the $\mathrm{CuO}$ in the place of $\mathrm{BaO}$ in which no acceptor or no donor in the A site of the perovskite structure of $\mathrm{BaTiO}_{3}$. Our current interest is to study the influence of copper on structural, dielectric and dc electrical resistivity properties, when it is substituted for Barium in $\mathrm{BaTiO}_{3}$ ferroelectric. The modified $\mathrm{BaTiO}_{3}$ ferroelectric materials are suitable for pyroelectric applications and hence copper has been chosen for modified $\mathrm{BaTiO}_{3}$ with different copper concentrations. The chosen problem for is to carry out the structural, dielectric and DC electrical resistivity measurements of with $\left(\mathrm{Ba}_{1-\mathrm{x}} \mathrm{Cu}_{\mathrm{x}}\right) \mathrm{TiO}_{3}$ with $\mathrm{x}=$ $0.01 \%, 0.02 \%, 0.03 \%$ and $0.04 \%$ concentrations.

\section{Experimental Techniques}

To characterize the prepared samples various experimental probes like XRD technique for structural properties, dielectric and dc electrical resistivity studies have been studied. Different compositions of $\mathrm{CuO}$ doped $\mathrm{Ba}-$ $\mathrm{TiO}_{3}$ with $\mathrm{Ba}_{1-\mathrm{x}} \mathrm{Cu}_{\mathrm{x}} \mathrm{TiO}_{3}$ ( $\mathrm{x}=0.01 \%$ to $0.04 \%$ ) polycrystalline compounds were prepared by solid state reaction method. All the raw materials $\mathrm{BaCO}_{3}, \mathrm{TiO}_{2}$ and $\mathrm{CuO}$ are analytical reagent grade of Loba Chemi, India with purity $99.5 \%$, were weighed by the stoichiometric equation $\mathrm{Ba}_{1-\mathrm{x}} \mathrm{Cu}_{\mathrm{x}} \mathrm{TiO}_{3}$ with $\mathrm{x}=0.01 \%, 0.02 \%, 0.03 \%$ and $0.04 \%$ respectively by using petit electronic balance MK-E series of $0.0001 \mathrm{gm}$ accuracy. Mixed powders with above compositions were hand ground in Agate mortar for 10 hours thoroughly for homogeneity. The homogenous mixtures of all these compositions were then pre-heated for calcination at $900^{\circ} \mathrm{C}$ in air for 12 hours. After calcinations these mixtures were examined for their structural studies with X-ray diffraction (XRD) (X-ray diffractometer of make Pan analytical) $\mathrm{Cu} \mathrm{K} \alpha$ radiation $(\lambda=1.541 \AA)$ at room temperature was used for structural studies of these samples.

The obtained mixed powders were again ground for 1 hour and granulated by adding PVA as binder, then pressed (with 250 mpa pressure) into pellets with diameter $12 \mathrm{~mm}$ and $2 \mathrm{~mm}$ thickness. Finally these pellets were sintered in air at $1100^{\circ} \mathrm{C}$, for 3 hours, followed by natural cooling to the room temperature. The prepared pellet sample surfaces were polished with carborundum powder for smooth and uniform surface and then the densities for all pellet shaped samples were measured. In order to measure their dielectric and dc electrical resistivity properties, silver paste was painted on both

The polished surfaces of the samples as an electrode and fired at $500^{\circ} \mathrm{C}$ for $15 \mathrm{~min}$. The Curie temperature $\left(\mathrm{T}_{\mathrm{c}}\right)$ for all the prepared pellet shaped samples was measured by obtaining the corresponding capacitance with the help of sensitive LCR meter accessed with variable temperature furnace. The dielectric properties of the pellets were determined using Hewlet Packard (Model 4192A) Impedance Analyzer from $100 \mathrm{HZ}$ to $13 \mathrm{MHZ}$ at room temperature.

Determining the D.C. electrical resistivity of a sample is another highly informative macroscopic measurement technique. A temperature dependent study of electrical resistivity yields activation energy of the charge carriers and when coupled with suitable models, this technique can yield important information regarding the nature of the charge carriers, type of charge transport and the nature of energy states involved etc.

In the present investigations the temperature dependence of D.C. electrical resistivity studies were carried out by using a two probe technique. A muffle furnace using a super canthal wire as a heating element is used for temperature variation studies in the range $300 \mathrm{~K}-460 \mathrm{~K}$. Temperatures of the furnace as well as the sample are monitored by using a $\mathrm{Cr}-\mathrm{Al}$ thermocouples. The resistance of the sample was measured using digital electrometer scientific equipment, Roorke model no DNM121.

The temperature dependence of D.C. electrical resistivities of the samples were studied with known geometry of the samples by applying the following equation.

$$
\rho=\rho_{0} \exp \left(-W / K_{B} T\right)
$$

$W$ is the activation energy, $K_{B}$ is the Boltzmann's constant and $T$ is the absolute temperature.

\section{Results \& Discussion}

$\mathrm{X}$-ray diffraction (XRD) is a versatile and non-destructive technique that yields the detailed information about crystallographic structure of the materials.

Figures 1(a)-(d) shows the x-ray diffraction patterns of the samples doped with different composition of $\mathrm{CuO}$ 


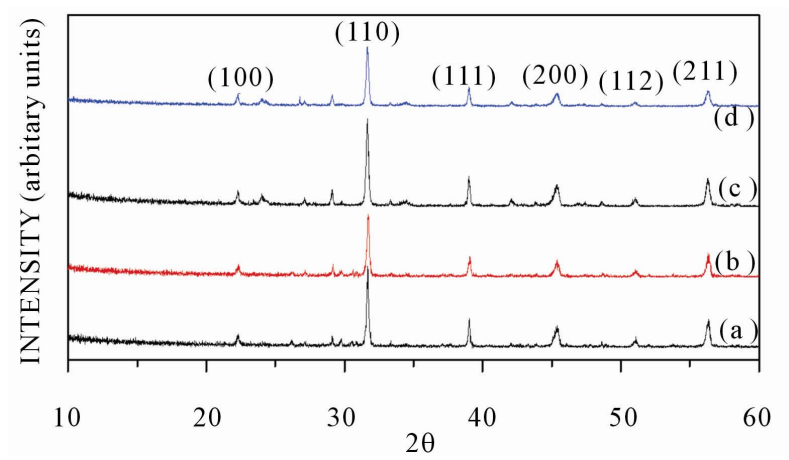

Figure 1. X-ray diffractograms of $\mathrm{Ba}_{1-x} \mathrm{Cu}_{x} \mathrm{TiO}_{3}$; (a) $\mathrm{x}=$ 0.01 ; (b) $x=0.02 ;$ (c) $x=0.03$; (d) $x=0.04$.

content of $0.01 \%, 0.02 \%, 0.03 \%$ and $0.04 \%$ respectively. It can be found that the positions and intensities of the diffracttion peaks are similar and no secondary phases were observed. All the above patterns of XRD show the single phase tetragonal system and similar to that of standard pattern of JCPDS of pure $\mathrm{BaTiO}_{3}$ with increase in $\mathrm{CuO}$ dopent in the place of Barium [15]. It indicates that influence of $\mathrm{CuO}$ did not affect the structural properties. Due to smaller concentrations of $\mathrm{CuO}$ doping in the place of Barium and both are of divalent ions may not affect the structural as $\mathrm{Cu}^{2+}$ ions replace $\mathrm{Ba}^{2+}$ ions. The lattice parameters of doped $\mathrm{BaTiO}_{3}$ with $\mathrm{CuO}$ are given in Table 1.

The relative densities of the sintered samples are 80.35, 76.71, 75.08 and 71.26 for $\mathrm{CuO}$ dopent content $\mathrm{x}=$ $0.01 \%, 0.02 \%, 0.03 \%$ and $0.04 \%$ respectively. C. Y. Chen and W. H. Taun reported the theoretical density of pure $\mathrm{Ba}^{-\mathrm{TiO}_{3}}$ is $6.02 \mathrm{~g} / \mathrm{cm}^{3}$ [16]. It was observed that the densities decreased with increase of $\mathrm{CuO}$ content even in small composition. It can be observed from the images of the scanning electron microscopy (SEM) shown in Figure 2. This may be due to replacement of $\mathrm{CuO}$ in $\mathrm{BaO}$ place. As the ionic radius of copper (II) is smaller than Barium (II), it leads to porosity in the samples and hence less densification. In contrast to the above, it was observed in literature that the densities of the $\mathrm{CuO}$ doped in $\mathrm{BaTiO}_{3}$ increased when $\mathrm{Cu}$ (II) was doped in Ti (IV) place [17].

Figures 3(a)-(d) show the variation of capacitance of the $\mathrm{CuO}$ doped samples with temperature. From Figure 3, the Curie's temperature for each composition of $\mathrm{CuO}$ doped $\mathrm{BaTiO}_{3}$ with $\mathrm{x}=0.01 \%$ to $0.04 \%$ was found to be in the range of $120^{\circ} \mathrm{C}$ to $125^{\circ} \mathrm{C}$. The corresponding dielectric constant values were also observed in Figures 4 (a)-(d) shows the variation of dielectric constant with temperature for $\mathrm{Ba}_{1-\mathrm{x}} \mathrm{Cu}_{\mathrm{x}} \mathrm{TiO}_{3}$ system, in which the dielectric constant values are in the range of 600 to 911 . The values of dielectric constant were decreased drastically when comparing with pure $\mathrm{BaTiO}_{3}$, whose value of dielectric constant is around 4100 at Curie temperature

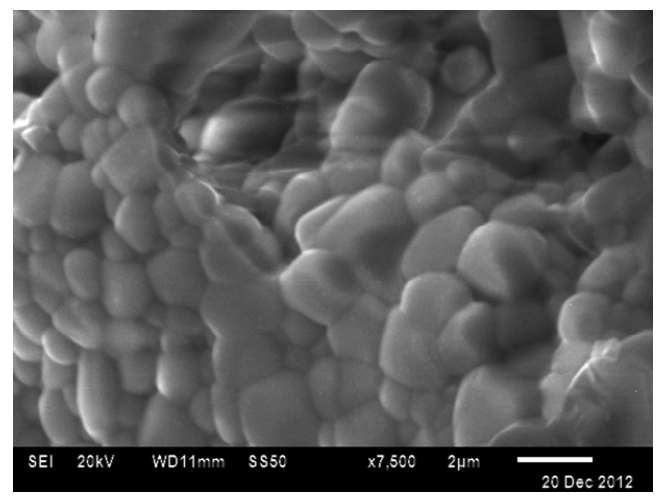

(a)

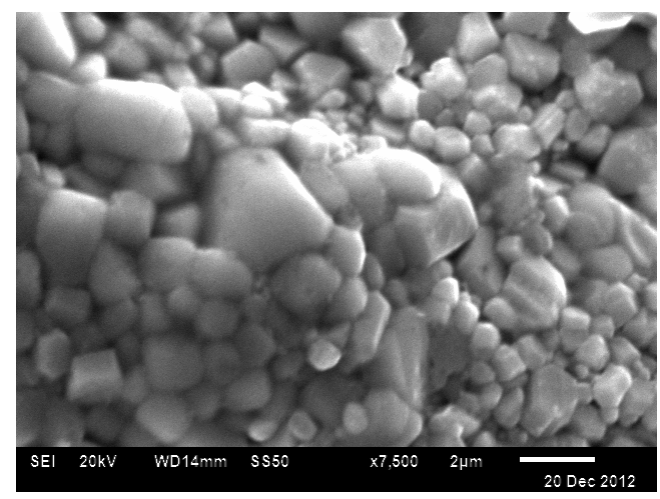

(b)

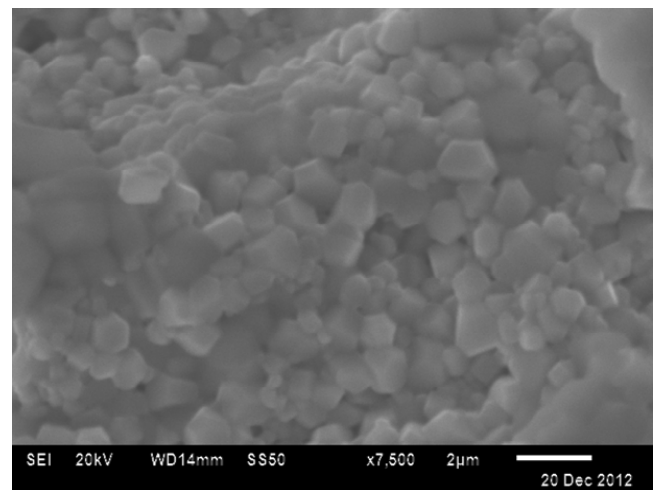

(c)

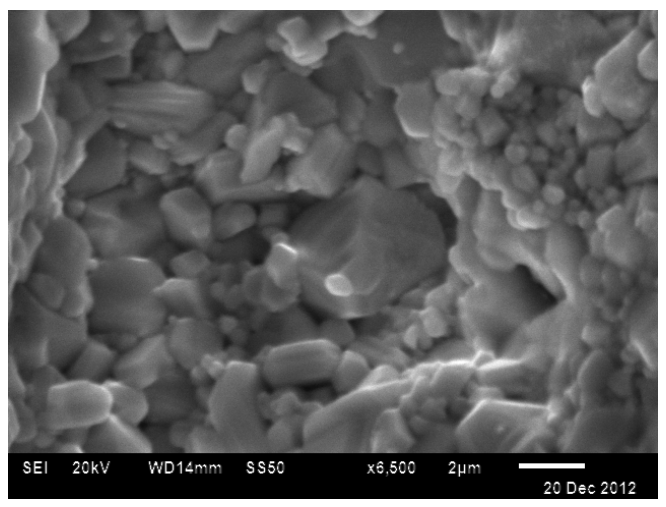

(d)

Figure 2. SEM pictures of $\mathrm{Ba}_{1-\mathrm{x}} \mathrm{Cu}_{\mathrm{x}} \mathrm{TiO}_{3}$ : (a) $\mathrm{x}=0.01$; (b) $\mathrm{x}$ $=0.02 ;$ (c) $x=0.03 ;$ (d) $x=0.04$. 
Table 1. Lattice parameters of $\mathrm{Ba}_{1-x} \mathrm{Cu}_{x} \mathrm{TiO}_{3}$.

\begin{tabular}{ccc}
\hline $\mathrm{X}(\%)$ & $\mathrm{a}(\AA)$ & $\mathrm{c}(\AA)$ \\
\hline 0.01 & 3.9865 & 4.0234 \\
0.02 & 3.9862 & 4.0237 \\
0.03 & 3.9836 & 4.0383 \\
0.04 & 3.9822 & 4.0412 \\
\hline
\end{tabular}

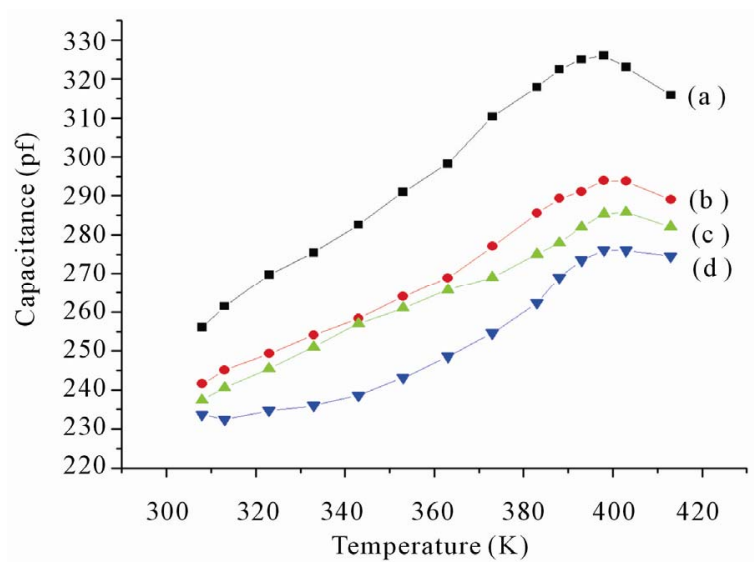

Figure 3. Variation of capacitance with temperature for $\mathrm{Ba}_{1-\mathrm{x}} \mathrm{Cu}_{\mathrm{x}} \mathrm{TiO}_{3}$ system; (a) $\mathrm{x}=0.01$; (b) $\mathrm{x}=0.02$; (c) $\mathrm{x}=0.03$; (d) $\mathrm{x}=\mathbf{0 . 0 4}$.

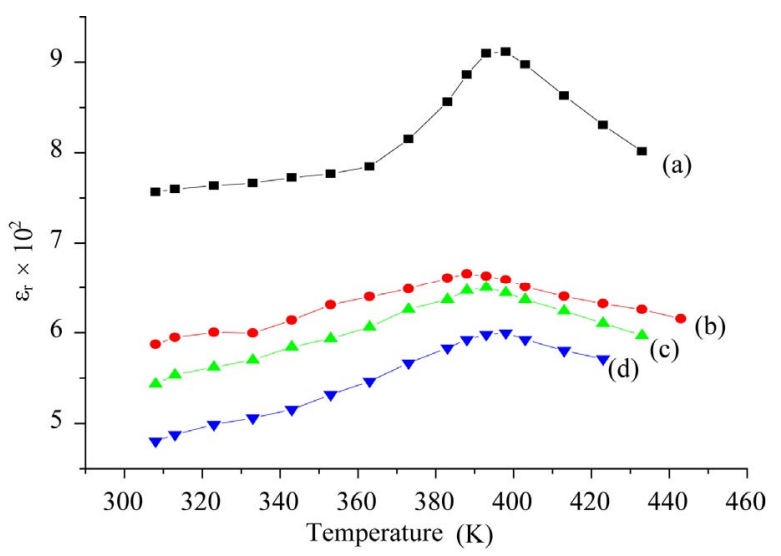

Figure 4. Variation of dielectric constant with temperature for $\mathrm{Ba}_{1-\mathrm{x}} \mathrm{Cu}_{\mathrm{x}} \mathrm{TiO}_{3}$ system; (a) $\mathrm{x}=0.01$; (b) $\mathrm{x}=0.02$; (c) $\mathrm{x}=$ 0.03 ; (d) $x=0.04$.

[17]. Even though Curie's temperatures for all the samples are maintained in the range around $120^{\circ} \mathrm{C}$, there is decrease in dielectric constant in all $\mathrm{CuO}$ doped samples. This might be due to the role of conducting Copper ions in $\mathrm{BaTiO}_{3}$ network in the place of Barium ions. Table 2 shows the values of dielectric constant and Curies' temperatures of $\mathrm{CuO}$ doped $\mathrm{BaTiO}_{3}$ samples.

The frequency dependence of relative permittivity (Dielectric constant, $\varepsilon_{\mathrm{r}}$ ) and dielectric loss (Tan $\left.\delta\right)$ of $\mathrm{Ba}_{1-\mathrm{x}} \mathrm{Cu}_{\mathrm{x}} \mathrm{TiO}_{3}$ samples at room temperature were given in Figures 5 and 6 respectively. From the Figure 5 it can
Table 2. Dielectric constant $\left(\varepsilon_{\mathrm{r}}\right)$ and Curie's temperature $\left(\mathrm{T}_{\mathrm{c}}\right)$ of $\mathrm{Ba}_{1-x} \mathrm{Cu}_{\mathrm{x}} \mathrm{TiO}_{3}$ samples.

\begin{tabular}{ccc}
\hline $\mathrm{X}(\%)$ & $\varepsilon_{\mathrm{r}}$ & $\mathrm{T}_{\mathrm{c}}\left({ }^{\circ} \mathrm{C}\right)$ \\
\hline 0.01 & 600 & 125 \\
0.02 & 650 & 120 \\
0.03 & 666 & 115 \\
0.04 & 911 & 125 \\
\hline
\end{tabular}

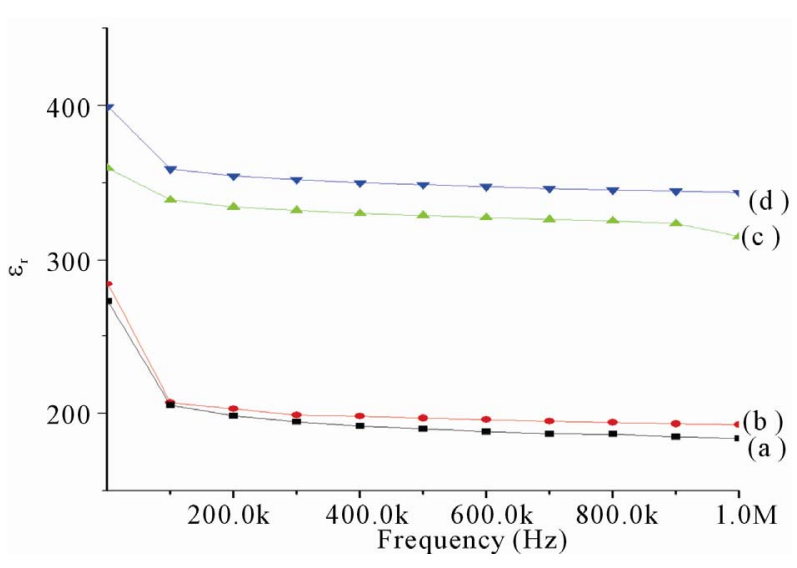

Figure 5. Frequency dependence of dielectric constant for $\mathrm{Ba}_{1-\mathrm{x}} \mathrm{Cu}_{\mathrm{x}} \mathrm{TiO}_{3}$; (a) $\mathrm{x}=0.01$; (b) $\mathrm{x}=0.02$; (c) $\mathrm{x}=0.03$; (d) $\mathrm{x}=$ 0.04 .

be observed that in all composition initially strong drop of dielectric constant up to $200 \mathrm{KHZ}$ and then slightly reduced up to $1 \mathrm{MHZ}$. The decrease in dielectric constant is due to the dipoles which cannot follow the alternation of the applied ac electric field at higher frequencies and then total orientation polarization is less at higher frequencies.

Figure 6 shows the frequency dependence of dielectric loss $(\operatorname{Tan} \delta)$ for all the prepared samples. It is obvious that the trend observed in dielectric loss decreases with increase of $\mathrm{CuO}$ content as the dielectric constant increases.

The D.C. electrical resistivities of the prepared samples were measured by using two probe techniques. The interest in D.C. electrical resistivity measurements is because of $\mathrm{CuO}$ doped in $\mathrm{BaTiO}_{3}$, as Copper is a good conducting ion in Barium titanate which may lead to transport by way of hopping. But here Copper is substituted in the place of Barium; our interest is how far Copper is involved in the transport mechanism. Figure 7 indicates the variation of D.C. electrical resistivity with temperature. From Figure 7, it can be observed that the D.C electrical resistivity decreased with increase of $\mathrm{CuO}$ content (from $0.01 \%$ to $0.04 \%$ ) up to certain temperature and then it increased. This trend was observed to be similar in all the compositions of the samples. Initially the decrease in D.C. electrical resistivity might be due to 


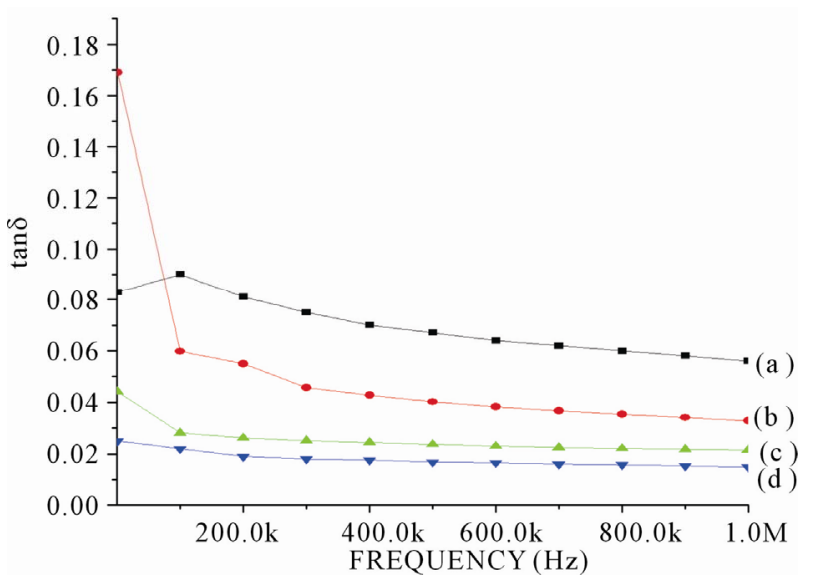

Figure 6. Frequency dependence of dielectric loss (Tan $\delta$ ) for $\mathrm{Ba}_{1-\mathrm{x}} \mathrm{Cu}_{\mathrm{x}} \mathrm{TiO}_{3}$; (a) $\mathrm{x}=0.01$; (b) $\mathrm{x}=0.02$; (c) $\mathrm{x}=0.03$; (d) $\mathrm{x}=$ 0.04.

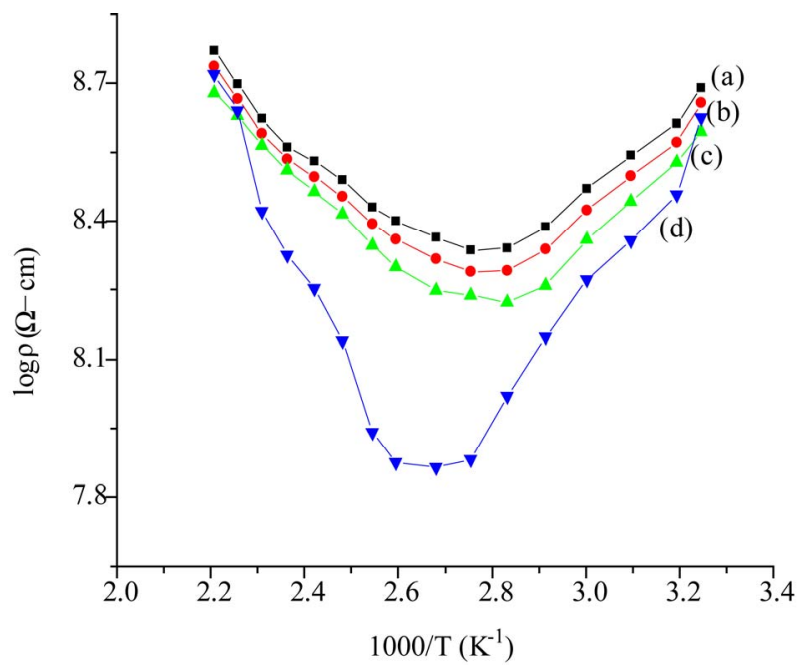

Figure 7. Temperature dependence of D.C. electrical resistivity of $\mathrm{Ba}_{1-\mathrm{x}} \mathrm{Cu}_{\mathrm{x}} \mathrm{TiO}_{3}$; (a) $\mathrm{x}=0.01$; (b) $\mathrm{x}=0.02$; (c) $\mathrm{x}=0.03$; (d) $\mathrm{x}=\mathbf{0 . 0 4}$.

participation of $\mathrm{Cu}^{2+}-\mathrm{Cu}^{+}$ions in the conduction process around their Curie's temperature and then increase of D.C. electrical resistivity. The increase in dc electrical resistivity at higher temperatures (i.e. above Curie temperature) is due to the contribution of hole conduction in all the samples which can be assumed to have been caused by the trapping of holes on Ba-O bonds. The similar trend was observed when applied to variable range hopping model mechanism also.

\section{Conclusions}

The present work was reports the study of preparation, experimental methodology and results in connection with structural, dielectric and DC electrical resistivity measurements of $\mathrm{CuO}$ modified $\mathrm{BaTiO}_{3}$ ceramics. As $\mathrm{CuO}$ and $\mathrm{BaO}$ were divalent so that $\mathrm{CuO}$ doped in the $\mathrm{BaO}$ place in pure $\mathrm{BaTiO}_{3}$ composition. Samples with $\mathrm{CuO}$ substituted $\mathrm{BaTiO}_{3}$ with stiochiometry $\mathrm{Ba}_{1-\mathrm{x}} \mathrm{Cu}_{\mathrm{x}} \mathrm{TiO}_{3}$, where $\mathrm{x}=0.01 \%, 0.02 \%, 0.03 \%$ and $0.04 \%$ compositions were prepared via solid state route. The structural properties of the $\mathrm{Ba}_{1-\mathrm{x}} \mathrm{Cu}_{\mathrm{x}} \mathrm{TiO}_{3}$ ( $\mathrm{x}=0.01 \%$ to $0.04 \%$ ) samples were explained from the X-ray diffractograms, indicate that the diffraction peaks are similar to the pure $\mathrm{BaTiO}_{3}$ and an influence of $\mathrm{CuO}$ in Barium titanate did not affect the structural properties.

The densities of the $\mathrm{Ba}_{1-\mathrm{x}} \mathrm{Cu}_{\mathrm{x}} \mathrm{TiO}_{3}$ ( $\mathrm{x}=0.01 \%$ to $0.04 \%$ ) samples are with less density compared to unsubstituted $\mathrm{BaTiO}_{3}$. This is due to the increase in porosity of the samples with small ionic radius of $\mathrm{Cu}$ ion in the place of $\mathrm{Ba}$ ion in " $\mathrm{A}$ " site. Curie's temperature of the $\mathrm{Ba}_{1-\mathrm{x}} \mathrm{Cu}_{\mathrm{x}} \mathrm{TiO}_{3}$ ( $\mathrm{x}=0.01 \%$ to $0.04 \%$ ) samples were found to be in the range $120^{\circ} \mathrm{C}$ to $125^{\circ} \mathrm{C}$. The corresponding dielectric constant values are in the range 600 to 910 . It was observed that with increase of $\mathrm{CuO}$ concentration the dielectric constant also increased. The frequency dependence of dielectricconstant and dielectric loss of $\mathrm{Ba}_{1-\mathrm{x}} \mathrm{Cu}_{\mathrm{x}} \mathrm{TiO}_{3}$ samples at room temperature were studied and they indicate that dielectric constant decreases with frequency. The dielectric loss decreases with increase of $\mathrm{CuO}$ content in the samples. The DC electrical resistivity of $\mathrm{Ba}_{1-\mathrm{x}} \mathrm{Cu}_{\mathrm{x}} \mathrm{TiO}_{3}, \mathrm{x}=0.01 \%$ to $0.04 \%$ ) ceramics were studied in the temperature range $300 \mathrm{~K}-460 \mathrm{~K}$. These results indicate that the $\mathrm{DC}$ electrical resistivity decreases initially upto nearer to their $\mathrm{T}_{\mathrm{c}}$ and then increased. It might be due to the participation of $\mathrm{Cu}^{2+}-\mathrm{Cu}^{+}$ions in the conduction process. The increase in resistivity can be attributed due to the contribution of hole conduction in all the samples, caused by the trapping of holes on $\mathrm{Ba}-\mathrm{O}$ bonds.

\section{REFERENCES}

[1] D. Makovec, Z. Samadmija and M. Drofenik, "Solid Solubility of Holmium, Yttrium, and Dysprosium in Ba$\mathrm{TiO}_{3}$," Journal of the American Ceramic Society, Vol. 87, No. 7, 2004, pp. 1324-1329. doi:10.1111/j.1151-2916.2004.tb07729.x

[2] D. Maga, P. Igor and M. Sergei, "Influence of Impurities on the Properties of Rare-Earth-Doped Barium-Titanate Ceramics," Journal of Materials Chemistry, Vol. 10, No. 4, 2000, pp. 941-947. doi:10.1039/a909647g

[3] J. Zhi, A. Chen, Y. Zhi, P. M. Vilainho and J. L. Batptista, "Incorporation of Yttrium in Barium Titanate Ceramics," Journal of the American Ceramic Society, Vol. 82, No. 5, 1999, pp. 1345-1348.

[4] Y. P. Pu, W. H. Yang and S. T. Chen, "Influence of Rare Earths on Electric Properties and Microstructure of Barium Titanate Ceramics," Journal of Rare Earths, Vol. 25, Suppl. 1, 2005, pp. 154-157. doi:10.1016/S1002-0721(07)60546-8

[5] A. Jane, T. K. Kundu, S. K. Pradhan and D. Chakravorty, "Dielectric Behavior of Fe-Ion-Doped $\mathrm{BaTiO}_{3}$ Nanoparti- 
cles," Journal of Applied Physics, Vol. 97, No. 4, 2005, Article ID 044311. doi:10.1063/1.1846135

[6] L. E. Cross, "Ferroelectric Ceramics: Materials and Application Issues," Ceramic Transactions, Vol. 68, 1996, pp. 15-55.

[7] V. Dharmadhikari and W. Grannemann, "Photovoltaic Properties of Ferroelectric $\mathrm{BaTiO}_{3}$ Thin Films rf Sputter Deposited on Silicon," Journal of Applied Physics, Vol. 53, No. 12, 1982, p. 8988. doi:10.1063/1.330456

[8] T. R. Shrout and J. P. Dougherty, "Lead Based $\mathrm{Pb}\left(\mathrm{B}_{1} \mathrm{~B}_{2}\right) \mathrm{O}_{3}$ Relaxors vs $\mathrm{BaTiO}_{3}$ Dielectrics for Multilayer Capacitors," Ceramic Transactions, Ceramic Dielectrics: Composition, Processing, and Properties, American Ceramic Society, Vol. 8, 1990, p. 3.

[9] G. H. Haertling, "Ferroelectric Ceramics: History and Technology," Journal of the American Ceramic Society, Vol. 82, No. 4, 1999, pp. 797-818. doi:10.1111/j.1151-2916.1999.tb01840.x

[10] W. Heywang, "Resistivity Anomaly in Doped Barium Titanate," Journal of the American Ceramic Society, Vol. 47, No. 10, 1964, pp. 484-490. doi:10.1111/j.1151-2916.1964.tb13795.x

[11] S. Chatterjee and H. S. Maiti, "A Novel Method of Doping PTC Thermistor Sensor Elements during Sintering through Diffusion by Vapour Phase," Materials Chemistry and Physics, Vol. 67, No. 1-3, 2001, pp. 294-297. doi:10.1016/S0254-0584(00)00454-5
[12] F. Batllo, E. Duverger, J. C. Jules and B. Jonnet, "Dielectric and EPR Studies of Mn-Doped Barium-Titanate," Ferroelectrics, Vol. 109, No. 1, 1990, pp. 113-118.

[13] V. C. S. Prasad and L. G. Kishore, "Studies on Some $\mathrm{BaTiO}_{3}$ Based Commercial Electroceramics," Ferroelectrics, Vol. 120, No. 1, 1990, pp. 141-150. doi: $10.1080 / 00150199008221472$

[14] F. D. Morrison, D. C. Sinclair and A. R. West, "An Alternative Explanation for the Origin of the Resistivity Anomaly in La-Doped $\mathrm{BaTiO}_{3}$," Journal of the American Ceramic Society, Vol. 84, No. 2, 2001, pp. 474-776. doi:10.1111/j.1151-2916.2001.tb00684.x

[15] W. Luan, L. Gao and J. Guo, "Size Effect on Dielectric Properties of Fine-Grained $\mathrm{BaTiO}_{3}$ Ceramics," Ceramics International, Vol. 25, No. 8, 1999, pp. 727-729. doi:10.1016/S0272-8842(99)00009-7

[16] C. Y. Chen and W. H. Tuan, "Effect of Silver on the Sintering and Grain-Growth Behavior of Barium Titanate," Journal of the American Ceramic Society, Vol. 83, No. 12, 2000, pp. 2988-2992. doi:10.1111/j.1151-2916.2000.tb01671.x

[17] T. Li, K. Yang, R. Z. Xue, Y. C. Xue and Z. P. Chen, "The effect of $\mathrm{CuO}$ Doping on the Microstructures and Dielectric Properties of $\mathrm{BaTiO}_{3}$ Ceramics," Journal of Materials Science: Materials in Electronics, Vol. 22, No. 7, 2011, pp. 838-842. 